\title{
Ethical and deontological issues in psychiatry
}

\author{
Anca Livia Chirita \\ Department of Psychiatry, University of Medicine and Pharmacy, Craiova, Romania
}

Email address:

ancaliviachirita@gmail.com

\section{To cite this article:}

Anca Livia Chirita. Ethical and Deontological Issues in Psychiatry. American Journal of Psychiatry and Neuroscience.

Vol. 2, No. 6, 2014, pp. 96-100. doi: 10.11648/j.ajpn.20140206.13

\begin{abstract}
General ethic principles in psychiatry are similar to those in somatic therapy, psychiatry being the medicine of the mind. The needs of the patient and society are the main focus of this medical specialty. Obtaining informed consent and cooperation can be encouraged if adequate information is disclosed to the patient from the outset. If the therapeutic measures that are being implemented (especially in case of, for instance, emergency admissions) are based on well-defined clinical data, the capacity of the patient to decide for themselves should be considered in addition to competency issues determined solely by the psychiatrist. Clinical experience has revealed that, unlike patients of other specialties, patients suffering from serious mental disorder often initially do not accept their clinical diagnosis, and subsequently may refuse much needed treatment. Temporarily, limiting the personal freedoms of the mentally ill are not just an end into itself, but an important means to ensure compliance with pharmacological and therapeutic objectives required for patient stabilization. The psychiatrist does so because, eventually, this would ideally restore the individual's rights to liberty, freedom and independent decision-making.
\end{abstract}

Keywords: Ethics, Deontology, Psychiatry

\section{General Principles}

Originally, deontology, (or etymologically speaking, the science of duty) is a philosophic concept. In psychiatry, nowadays, this term is used to define the way in which moral standards in professional practice are found at the crossroads of ethics and law. Ethics classically then distinguishes between the good and the bad and law between what is right and wrong. Unlike deontology, ethics corresponds to a set of principles of professional morality related to a wider area and focuses on principled issues, whose answers may not be easily codified into ethics for various professions.

Medical deontology dates back in ancient times and its illustrative influences are the Hippocratic Oath and the Prayer of Maimonides. Likewise, medicine is one of the first liberal professions that looked into codification of specific laws applicable in clinical practice. But not until the 20th century, during the interwar period, medical trade unions began publishing a code of ethics and in 1941 Doctors' Order, recently established, published the first code of professional ethics. Previously intended as a simple internal regulation, the code was enacted in 1947 as a decree regulated by the local governments and revised in 1955 and in 1979. Within European Community, Germany, Belgium, Spain and Italy have their own codes of medical deontology, whereas in the other countries specific regulations obey aspects of jurisprudence [1, 2].

In 1978, the General Assembly of the World Psychiatric Association reunited in Hawaii, and set out 10 ethical guidelines, included in a declaration intended for psychiatrists world-wide $[3,4]$. These rules were meant to represent the minimum requirements of ethical standards for the psychiatric profession. In 1983, these rules were revised by the General Assembly of the American Psychiatric Association (APA) in Vienna, to reflect the impact of changing social, cultural, legal and economic attitudes emerging universally [5]. The Declaration of Madrid undertook a new review of the said principles in 1996 [6]. Mainly, the standards stipulated in the Declaration are listed below:

- Psychiatry is concerned with the provision of the best possible treatment for mental disorders, the recovery and the promotion of mental health.

- It is the duty of psychiatrists to keep abreast of scientific developments of their specialty.

- The patient should be accepted as a partner by right in the therapeutic process.

- When the patient is seriously disabled or unable to exercise proper judgment because of a mental disorder, 
the psychiatrist should consult with the family and, if needed, to seek legal aid, to safeguard the human dignity and the legal rights of the patient. Treatment must always be in the best interest of the diseased.

- When psychiatrists are requested to assess a person, it is their duty to inform the person being assessed about the purpose of the intervention, the use of their findings and the possible repercussions of the assessment.

- Information obtained in the therapeutic relationship must be confidential and used exclusively with the aim of improving the mental health of the patient.

- Research that is not conducted in accordance with the canons of science is unethical. Research activities should be approved by an appropriate committee made up of individuals with the proper research training. Because psychiatric patients constitute a particularly vulnerable research population, extra caution should be taken to safeguard their autonomy and their mental and physical integrity.

The declaration officially approved by the General Assembly of United Nations in 1991 protecting the mentally ill is another example of international initiative. Those 25 principles were stipulated in the declaration approach, for example, assessment and treatment procedures, privacy and informed consent - the consent based on the full knowledge of the facts [7].

In 1996, WHO draws an act entitled "Public Mental Health: guidelines for development and management of national mental health schemes". This is a written, practical tool, intended for decision-makers, who set out eight main elements which underlay mental health policies nationally: decentralization, intersectorial action, comprehensiveness, equity, continuity, community participation, mechanisms for policy formulation and implementation and selection of priorities [8]. The same year, the Department of Mental Health and Substance Abuse within the World Health Organization outlines a document listing ten basic principles, with annotations for their implementation in practice [9].

Table 1. Principles of mental health schemes

\begin{tabular}{ll}
\hline At geographical level & Basic WHO principle \\
\hline Country/region & $\begin{array}{l}\text { Promotion of mental health and prevention of } \\
\text { mental disorders } \\
\text { Respect of rules of law }\end{array}$ \\
& $\begin{array}{l}\text { Access to basic mental health care } \\
\text { Availability of review procedure } \\
\text { Automatic periodical review mechanism } \\
\text { Qualified decision-maker }\end{array}$ \\
& $\begin{array}{l}\text { Mental health assessment in accordance with } \\
\text { internationally accepted principles } \\
\text { Provision of less restrictive type of mental } \\
\text { health care } \\
\text { Self-determination } \\
\text { Right to be assisted in the exercise of } \\
\text { self-determination }\end{array}$ \\
\hline
\end{tabular}

\section{Informed Consent in Psychiatry}

Proper medical practice implies and necessitates patients' trust in their therapist. It is mandatory to inform the patient on initial contact of the procedure that will be implemented. Furthermore for some classes of psychiatric patients, there could potentially be information that would lend itself to a stigmatized diagnosis. Such ostensibly "negative diagnosis" could potentially undermine the therapeutic doctor-patient relationship. Therefore, in these cases, initial full disclosure of all reasons for treatment may be ill-advisable.

Provision of exhaustive information is not enough; psychiatrists must make sure that the patient has a clearly understood meaning of the information that is appropriate to their level of understanding. A question ripe for discussion is if providing too many details to the patient might harm the therapeutic relationship. Thus future studies carried out within the context of general practice might be helpful if they illustrated how the provision of basic information might aid optimal decision-making $[10,11]$. However, a literature review did not reveal if any psychiatric studies had been carried out in this area.

There are special regulations pertaining to informed consent obtained from adults. Unfortunately there are no hard and fast rules of protocol for psychiatrists when for instance delirious patients are voluntarily admitted. It is highly unlikely that this type of patient, who has lost touch with reality, could understand the reasons for therapeutic behavior. In critical situations, informed consent can be obtained from third parties instead of the patient concerned. It is not always possible in psychiatry however to gain familial consent given that education and other variables may limit whether family could understand the information needed to authorize consent on the patient's behalf.

Likewise, oftentimes paranoid patients for instance may look suspiciously every time they are required to sign committal documents, thereby refusing to give their consent, thinking that might put them at psychiatrists' disposal.

Consent must contain fair information, in transparent terms, which is easy to understand. Even if information provision aims at revealing the actual physical condition of the patient, it is recommended to choose the right circumstances to disclose clinical data to the patient in order to avoid anxiety.

In psychiatry, there are several factors that influence the way in which the patient might perceive disclosure. These factors are correlated, on the one hand with the pathologic disease process itself, but on the other hand, with the peculiarities of physician-patient relationship and the patient's family role in that relationship. In some cases, negative cognitive distortions can prevent the patient from fully understanding the information that is being disclosed to her or him. In other instances patients refuse any psychiatric treatment because they may be convinced that their disease cannot be cured (such as melancholy) or alternatively the patient may be suffering from delirium, which alters the way reality is construed. 


\section{Ethical Issues in the Relationship between Physician and Psychiatric Patient's Family}

Relatives of patients with mental disorder may be a valuable resource, leading to an individual assessment of the psychiatric patient. Medical literature from the last two decades has praised specific methods and techniques that assess the impact of family role in the evolution of the disease $[12,13]$.

One of the most common ethical misconceptions that a psychiatrist may get when evaluating a patient is an "a priori belief" (based, subjectively, on the patient's statement) that the family is the one

responsible for disorder onset or relapse episodes. Although there is data stating that relapses of schizophrenia can be triggered, for example, by a negative family environment, there is no proof that familial actions may cause de novo disorder [14]. Conversely, family alienation has been deemed to be a poor predictor of multiple relapses in people with schizophrenia [15].

The concept of "expressed emotion" measures the level of criticism and is a widely used construct in familial studies of schizophrenia [16]. Expressed emotions (EE) has been shown to be predictive of outcome in mental illness relapses. Families with high level of EE and insufficient knowledge of the disease were the main cause for the lack of treatment compliance [17]. In other words, relatives with high EE level showed low self-esteem themselves, they are less flexible, less tolerant and empathetic, more judgmental, with negative autobiographical obsessions and they often present abnormal subclinical behaviour [18]. Moreover, recent studies show that EE can potentiate individual relapse [19].

Another error would be disregarding the varied mental health of relatives, which interferes directly with patient's mental health; in other words, in most of the cases, both the patient and his family may alter their health condition. Strangely enough, sometimes the family shows discomfort and suffering when the patient's symptoms tend to improve and when she or he becomes independent sooner than the family expects [20].

Another inaccurate approach is the way in which the psychiatrist sees the principle of confidentiality, dealing with it in a way that may harm both the patient and his family. There are cases when clinical staff choose not to inform the family of important data, such as the diagnosis, outcome of the disease, possible side effects, current treatment and available therapeutic options, on the assumption that such information is confidential and cannot be disclosed to a third party without the patient's consent. Even if this is seen as a legal requirement and an indicator of good medical practice, clinical staff ignore the fact that relatives may not support the patient properly, if they are purposely denied access to relevant data.

\section{Ethical Aspects in Clinical Psychiatric Trials}

In Europe, in 1941, a new legislation concerning pharmaceutical studies starts to develop, based on a series of previous articles, ordinances and decrees (ethical norms and standards for research involving human subjects which were implemented in Germany, for example, since 1931) [21]. Last century, in the $1980 \mathrm{~s}$, ethics committees and publication of the first guidelines of good clinical practice (Good Clinical Practice-GCP) in 1987 enhanced clinical methodologies and procedures.

Biomedical research is "a trial conducted on human subjects, with or without direct benefits". The major participants in the research are the sponsors, investigators and subjects. The aim of ethic committees at different levels (institutional, local, regional, national and international) is twofold: 1) to ensure that trials are adequately designed to meet scientifically sound standards; 2 ) to protect the rights of the subjects involved. Legal principles of legislation concerning clinical trials lay out the following requirements:

- Pertinent scientific research should be considered an essential element of medical ethics and most important, the deontological basis of each clinical trial.

- Risks should be weighed against the anticipated therapeutic benefits.

- Investigators that conduct and monitor the trials must be doctors (specialists with practice authorization in that country) and they must be experienced in clinical trial research.

- Material, financial and technical responsibilities of the sponsors must be clearly outlined.

- Material and technical conditions of experimental trials should be in accordance with rigorous scientific provisions and respect the safety of the individuals.

- Before proceeding with any trial, the subject of biomedical research should sign, fully aware of the facts, an informed consent. It is noteworthy that this-principle was first enunciated in 1947, in the provisions of the Nuremberg Code.

- Organization, functioning and financing of ethics committees must be specified.

- Obligations and roles of investigators are clearly defined.

- Biomedical research without implying direct individual benefit is approved only in special cases.

GCP guidelines assess the quality and accuracy of scientific data resulting from trials, ensuring ethical requirements are observed and the safety of patients protected. The duties of sponsors, investigators and ethics committees are subject to a permanent control procedure (audit). Three basic rules should be respected, regardless of the nationality of those who promote clinical trials: subject's informed consent, scientific role of research, approvals of the protocol by relevant ethics committees. 
In psychiatry, more than in any other medical specialty, organizing clinical trials is subject to the following conditions. Psychiatric patients are highly susceptible and sensitive and a great part of them will refuse from the start to participate in studies, even though investigator has valid arguments. Conversely, a series of investigators may be inclined to refuse the inclusion of certain classes of patients which potentially could skew the experimental results. In this way, the subjects participating in the clinical trial will not be represent the population affected by the respective disease. Also, there are some countries that dispute the validity of the informed consent signed by patients with mental disorders.

In a double-blind trial, the investigator himself will not be able to explain to the patient the side effects and the outcomes of the study, so the patient may not be completely informed of the treatment.

Since the beginning of the last century, before pharmaceutical clinical trials ever appeared, psychiatrists have been trying, by various methods, to combine assessments of psychiatric symptomatology with markers of pathophysiological processes. Moreover, quantification of psychiatric symptoms with rating scales has certain limitations. For example, the Hamilton Depression Rating Scale (HAM-D), the most used instrument in clinical trials for depression, includes various items that measure symptoms also presents in patients with anxious disorders, phobias, post-traumatic stress disorders etc. [22].

At present, efforts are being made to evaluate effects of study drugs by the use of parameters that explain the etiology and pathophysiology of the disease, rather than by using rating scales. For example, it has been suggested that rapid eye movement sleep (REM) was used as marker of antidepressant or cholinergic response to Alzheimer disease [23].

Clinical studies have shown a high rate of placebo responses in clinical trials, with important ethical implications [24]. This could be construed as challenging various ethical givens, implying that patients recruited in the trial do not meet inclusion criteria, due to low disease severity (maybe because investigators have the misconception that severely ill patients would not tolerate placebo administration during the study period). On the other hand, we must also consider the natural evolution of the acute episode by spontaneous remission. This has led to a failure of a series of trials conducted for post-traumatic stress disorder, whose natural evolution is spontaneous remission during the first year, even in the absence of a psychotropic treatment [25].

Another aspect in psychiatric studies is the fact that, usually, mental illnesses present a high degree of heterogeneity, comorbidities being frequent in specific conditions (for example, comorbid major depression is frequently associated with post-traumatic stress disorder). Therefore, a homogeneous group of patients can hardly ever be organized [26].

Current protocols of multicenter clinical studies presuppose a large cohort of patients, in order to obtain significant results, especially in psychiatry, where patients present totally different clinical symptoms. On the other hand, a high number of subjects participating in the clinical trial may raise ethical concerns, identifying possible side effects at a larger number of individuals, with no therapeutic benefit. Regulatory agencies are focused on finding new highly efficient drugs for the patients, but also on improving their safety and reducing the impact of side effects. Regulatory agencies are always in search for new solutions, such as established animal models of human mental disease, one of the heavily evolving research techniques of the last decade [27]. Moreover, the Canadian Code of Ethics for Psychologists has a special section concerning care of animals, establishing that it is not recommended to use animals in research "unless there is a reasonable expectation that the research will increase understanding of the structures and processes underlying behavior" [28].

\section{References}

[1] Petitjean F, Cordier B. Deontologie et psychiatrie. Editions Techniques, Encycl Med Chir Paris France, 37061A, 1991.

[2] Daumezon G. Psychiatrie et ethique. Evol Psychiatr, 1989, 44:115-129.

[3] World Psychiatric Association. Declaration of Hawaii. J Med Ethics, 1978, 4:71-73.

[4] Thornicroft G, Tansella M. Bazele etice ale serviciilor de sănătate mintală: „cei trei ași (ACE)”. In Thornicroft G, Tansella M eds. Modelul matriceal al sănătății mintale. Editura Medicală București; 2001. p. 146-148.

[5] World Psychiatric Association. Declaration of Hawaii/II. WPA General Assembly, Vienna, 10th July 1983.

[6] World Psychiatric Association. Declaration of Hawaii/III (Revised at the General Assembly of Madrid); 1996.

[7] United Nations. Protection pf persons with mental illness and improvement in mental health care. Resolution UN/GA/46/119; New York, United Nations, 17 December 1991 International Digest of Health Legislation, 43:2.

[8] World Health Organization. Public mental health: Guidelines for the elaboration and management of national mental health programmes. Geneva; WHO Division of Mental Health and Prevention of Substance Abuse; 1996.

[9] World Health Organization. Mental health law: ten basic principles. Geneva, WHO; 1996.

[10] Poirier-Littre MF, Ginestet D. Legislation des essais therapeutiques. Edition Techniques, Encycl Med Chir; Paris, France 37040B, 1991.

[11] Dahan R, Caolin C, Figea L, Kanis JA, Caolin F, Segrestaa JM. Does informed consent influence therapeutic outcome? A clinical trial of the hypnotic activity of placebo in patients admited to hospital. Br Med J; 1996, 293:363-364.

[12] Kuipers L, Bebbington P. Working in partnership: clinicians and carers in the management of long-term mental illness. London: Heineman; 1991.

[13] Schene A, Tessler K, Gamache G. Instruments measuring family or care giver burden in severe mental illness. Soc Psychiat and Psychiat Epidemiol; 1994; 29:228-240. 
[14] Keitner GI, Kurimay T, Wilson AK. Advances in family research and intervention. In: Christodoulou GN editor. Advance in psychiatry. 2005, Vol. 2:127-134.

[15] Bebbington PE, Kuipers E. Schizophrenia and psychosocial stresses. In: Hirsch SR, Weinberger D eds. Schizophrenia, psychosocial aspects. Oxford UK: Blackwell; 2003. p. 615-622.

[16] Asen E. Outcome research in family therapy. Advances in psychiatric treatment. 2002; 8:230-238.

[17] Hooley JMR, Hiller JB. Personality and expressed emotion. J Abnorm Psychol. 2000; 109:40-44.

[18] McFarlane WR. Multifamily groups in the treatment of psychiatric disorders. New York: Guilford; 2002.

[19] Vixon MJ, King S, Stip E, Cormier H. Continuous performance test differences among schizophrenic outpatients living in high and low expressed emotion environments. Psychol Med. 2000; 30:1141-1153.

[20] Ryan CE, Epstein NB, Keitner GI. Evaluating and treating families: the McMaster approach. New York: Brunner/Mazel; 2005.

[21] Loue S, Ioan BG. Repere istorice în cercetarea pe subiecți umani. In: Astărăstoaie V, Loue S, Ioan BG eds. Etica cercetării pe subiecți umani. Iași: Editura Gr. T. Popa; 2009. p. 9-10.
[22] Crocq MA, Macher JP, Luthringer R. Recent developments in the metodology of drug development. In: Christodoulou GN editor. Advances in Psychiatry. Vol. II, 2005, p. 95-99.

[23] Staner L, Luthringer R, Macher JP. Effects of antidepressant drugs on sleep EEG in patients with major depression. Mechanisms and therapeutic implications. CNS Drugs, 1999, 11:49-60.

[24] Khan A, Leventhal RM, Khan S, Brown WA. Severity of depression and response to antidepressants and placebo: an anlysis of the Food and Drug Administration data base. J Clin Psychopharmacol. 2002; 22:1-6.

[25] Gilles C, Schunk T, Erb G. Human models as tools in the development of psychotropic drugs. Dialogues Clin Neurosci. 2002; 4:377-387.

[26] Lebowitz BD. A public health approach to clinical therapeutics in psychiatry: directions for new reasearch. Dialogues Clin Neurosci. 2000; 2:309-314.

[27] Lipska BK, Aultman JM, Verma A, Weinberger DR, Moghaddam B. Neonatal damage of the ventral hippocampus impairs working memory in the rat. Neuropsychopharmacol. 2002; 27:47-54.

[28] Canadian Psychological Association. Canadian Code of Ethics for Psychologists - Third Edition. Ottawa - Canada: Canadian Psychological Association, 2000. 